\title{
Impression Creep Behavior in Weldments
}

S.H. Wang

Department of Mechanical and Marine Engineering National Taiwan Ocean University Keelung 20224, Taiwan, Republic of China

Follow this and additional works at: https://jmstt.ntou.edu.tw/journal

Part of the Mechanical Engineering Commons

\section{Recommended Citation}

Wang, S.H. (1994) "Impression Creep Behavior in Weldments," Journal of Marine Science and Technology. Vol. 2: Iss. 1 , Article 3.

DOI: $10.51400 / 2709-6998.2484$

Available at: https://jmstt.ntou.edu.tw/journal/vol2/iss1/3

This Research Article is brought to you for free and open access by Journal of Marine Science and Technology. It has been accepted for inclusion in Journal of Marine Science and Technology by an authorized editor of Journal of Marine Science and Technology. 


\title{
IMPRESSION CREEP BEHAVIOR IN WELDMENTS
}

\author{
S.H. Wang \\ Department of Mechanical and Marine Engineering \\ National Taiwan Ocean University \\ Keelung 20224, Taiwan, Republic of China
}

\begin{abstract}
Key words: heterogeneous, impression creep, inhomogeneous, weldment, composite.
\end{abstract}

\begin{abstract}
At high temperature application, the failures of dissimilar metal weldments associated with the relevant degradation processes, which include chemical diffusion, oxide notching, precipitation, softening of the heat affected zone (HAZ), and creep type voids leading to cracking. This reveals that a creep in a gradient related to the microstructural degradation exists. The impression creep test was applied to monitor the effects of microstructural gradients on the localized high temperature creep properties in an autogeneous GTA aluminum weldment, and an austenitic stainless steel to ferritic steel dissimilar metal weldment respectively. To simplify the complexity of microstructural gradients, multipass weldments in A36 steel were produced. The local creep properties as a function of position were evaluated by impression creep test. A qualitative analysis of $\mathrm{Q}_{c}$ and $\mathrm{n}_{\mathrm{c}}$, based on two-component composite model, was conducted at the interface region of the solidified weld metal and the reheat affected zone.
\end{abstract}

\section{INTRODUCTION}

Microstructural gradients develop as a normal consequence of welding. Chemical gradients develop within the solidified weld metal due to solidification induced coring. Correspondingly a heterogeneous solidified microstructure evolves which depends on the chemical profiles. In addition to the composition gradients, a thermal gradient in the heat-affected zone adjacent to the fusion line or between passes in multipass weldments can also induce heterogeneous solid-state transformed microstructures. As a result, the mechanical properties of weldments are complex and reflect the position dependent variations in microstructure related composition profiles or microstructure related thermal profiles.

Mechanical testing of weldments normally involves the use of standard sample geometries. Which, when machined from weldments, include a complex microstructural gradient. To evaluate the effects of the microstructural gradient on properties, several mechanical test technique have been utilized, the simplest of which is the standard hardness test. More recently, Tanaka, Sato and Ishikama [1] developed a specialized fracture me- chanics test which is sensitive to toughness variations with position within the microstructural gradient associated with a weldment. Specially their tests involved the evaluation of crack opening displacement when a stable fatigue crack developed an instability in the presence of a localized brittle zone.

The strain distributions during creep associated with the microstructural gradients in an austenitic stainless steel to $21 / 4 \mathrm{Cr}-1$ Mo steel dissimilar metal were recently evaluated with a specialize microgrid modeling technique [2]. Microstrain distribution in cross-weld test pieces illustrated that strains increased rapidly to a value of about $25 \%$ at about 100 um from the fusion boundary, then decreased gradually to the value of the creep strain in the parent material [2]. The position of maximun strain coincided with the location of cracking in the HAZ.

Recently numerical modeling of creep analysis in dissimilar metal transition joints was used by Even and Wilshire [3] to predict the stress and strain inhomogeneities within the heterogeneous heat affected zone. However, due to the complexity of the formulation, their results are not applicable to actual service conditions which include time dependent change in stress, temperature, microstruc- 
ture, and composition.

The mechanical behavior of individual zones within the heterogeneous weldment are usually evaluated with either sub-sized mechanical test specimens such that the gage length includes only material from a specific region within the weldments, or bulk samples with microstructures which are processed to simulate those observed at specific locations within the weldment.

However, subsized specimens are limited by the minimum size requirement of a specific region within the weldments for machining. Due to the effects of compositional segregation, microstructural simulation is limited by the ability to properly define $t$ he local composition and microstructure of the zone of interest within the microstructural gradient. In addition, in the case of the limited size of the zones of interest, definition of the local temperature history is difficult. Besides the microgrid technigue [2], impression creep testing is an alternative method to evaluate inhomogeneous properties and is the basic for this research.

\section{IMPRESSION CREEP TESTING}

The impression creep test technique is essentially a modified hot hardness test in which the displacement of a cylindrical punch as a function of time under a constant load and thus a constant stress is measured. The impression test is shown schematically in Fig. 1. The punch penetration rate (referred to as the impression velocity) is controlled by the time dependence of the movement of mass from under the punch, and thus directly monitors the creep characteristics of a localized volume of material indicated by the deformed zone in Fig. 1. The

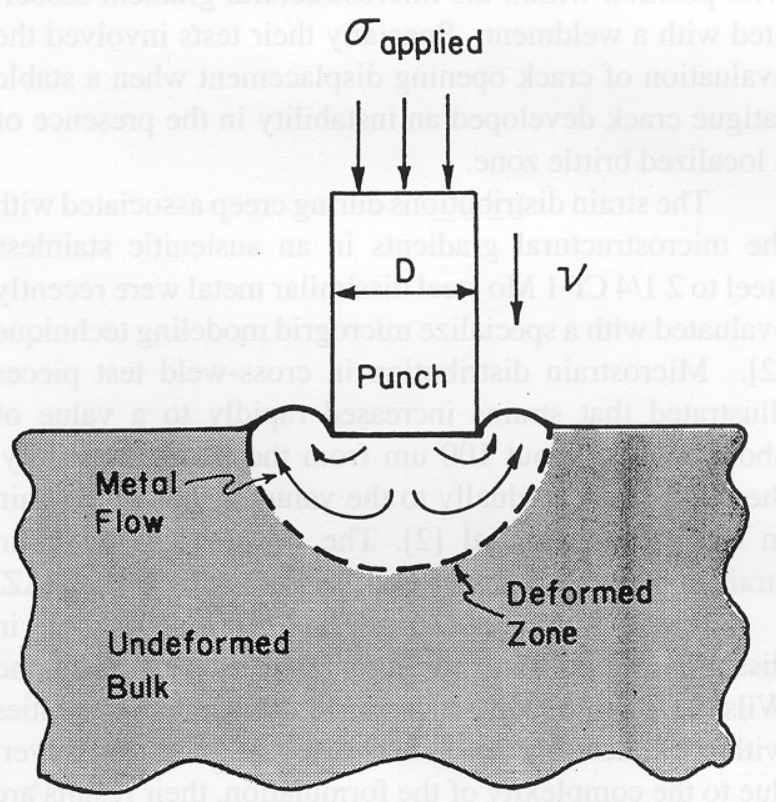

Fig. 1. A schematic illustration of the deformation field around a punch during impression creep testing. steady state impression velocity exhibits the same stress and temperature dependence as the steady state creep rate in conventional tensile creep. Equivalency between impression creep testing and conventional creep testing has been demonstrated [4]. And thus, punch displacement and impression velocities are directly analogous to conventional creep strain and creep rates.

The impression creep test [4] was applied to monitor the effects of microstructural gradients on the localized high temperature creep properties in weldments. Gibbs et al $[5,6]$ demonstrated that transitions in creep properties correlate with microstructure gradients which were observed in an autogeneous GTA aluminum weld. These results are summarized in Fig. 2, a plot of impression velocity at a constant stress and temperature, across an aluminum weldment. Similar correspondance between creep properties and microstructure was demonstrated in an austenitic stainless steel to ferritic steel dissimilar metal weldment. In the dissimilar metal weldment, the maximum impression creep velocity occured in the heat-affected zone as illustrated by the impression creep profile shown in Fig. 3. In addition as shown in Fig. 3, the

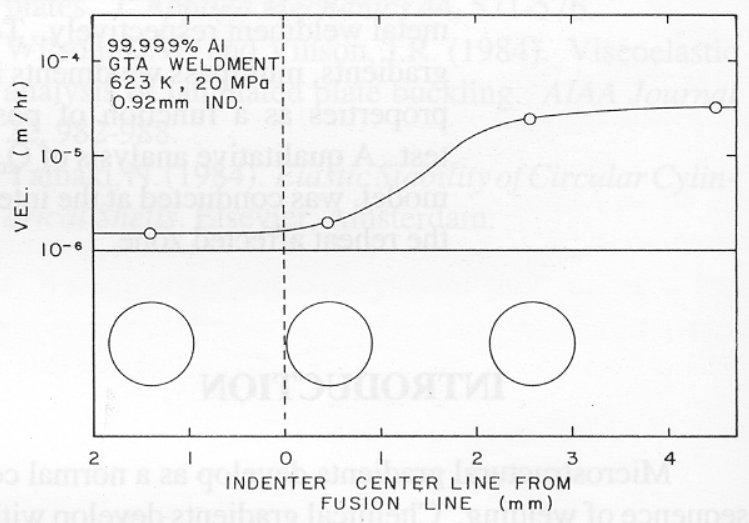

Fig. 2. Punch velocity versus distance from the fusion line for pure AL autogeneous GTA weldment [5].

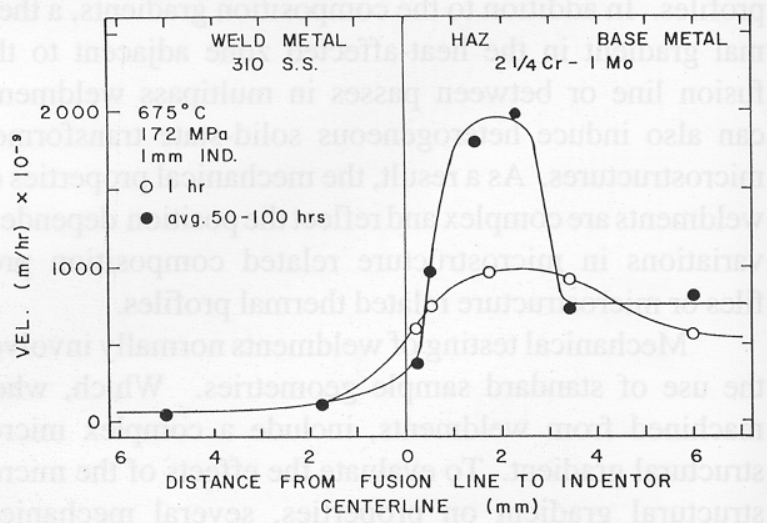

Fig. 3. Punch velocity vs. distance from the fusion line for $21 / 4 \mathrm{Cr}-1 \mathrm{Mo}$ steel to type 316 stainless steel weldment joined with type 310 stainless steel filler metal [5]. 
maximum impression velocity in the region increased with time owing to the effects of carbon depletion in the zone shown previously to be susceptible to creep cracking in service. The microstructural gradients which correspond to the impression creep data of Fig. 3 are shown in Fig. 4, for the as-welded condition and in Fig. 5 after aging for 120 hours at $675^{\circ} \mathrm{C}$.

A schematical illustration of the complex microstructural zones associated with a weldment is shown in Fig. 6 and illustrates a complex structural gradient as- sociated with the decarburization profile, which is plotted at the top of the figure. These complex heterogeneous microstructures can be roughly divided into several regions:

(1) Carbon depleted coarse grain zone

(2) Coarse grain zone

(3) Equiaxed fine grain zone

(4) Tempered base metal zone

(5) Base metal

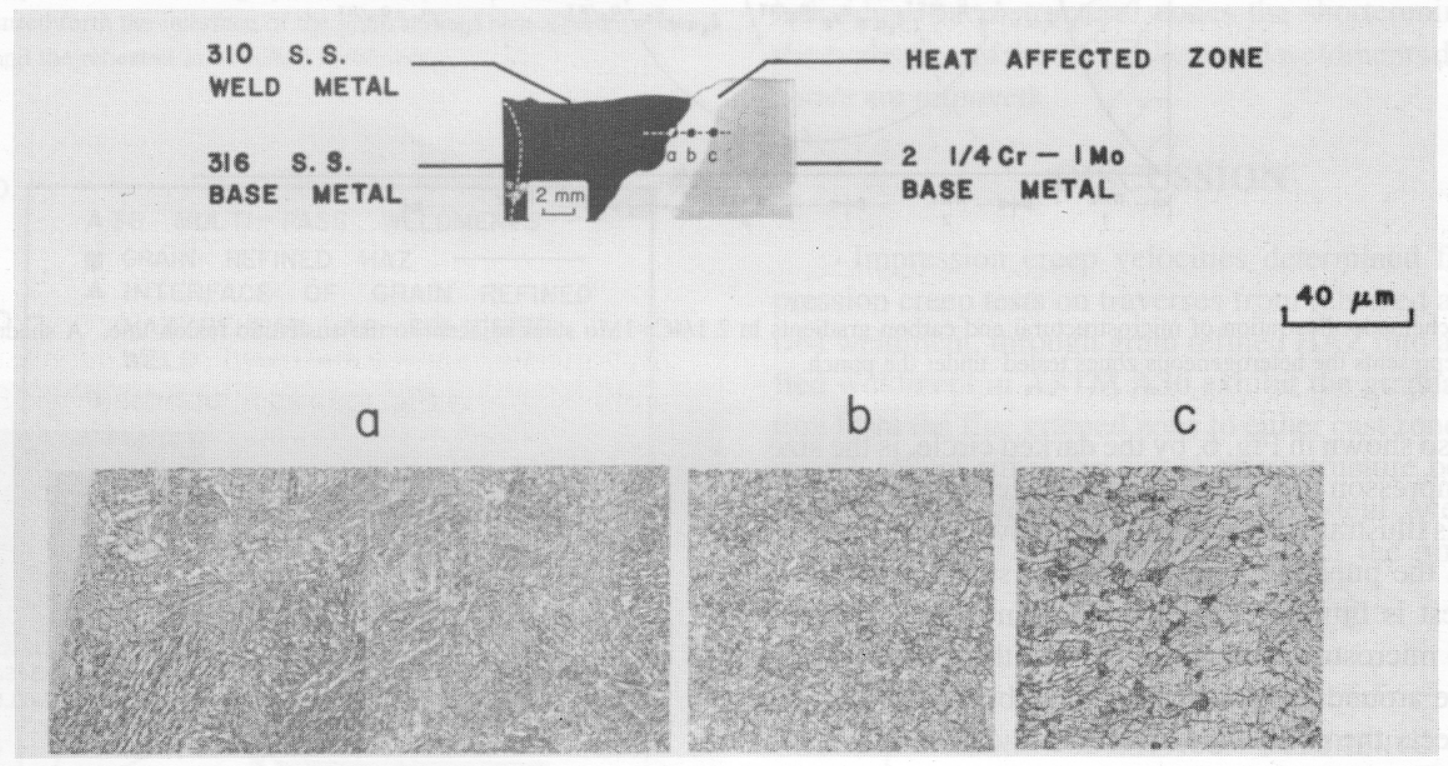

Fig. 4. As welded microstructures of a $21 / 4 \mathrm{Cr}-1 \mathrm{Mo}$ steel to type 316 S.S. dissimilar weldment joined with type 310 S.S. filer wire. (a)adjacent to the fusion line, (b) $1.1 \mathrm{~mm}$ from the fusion line, (c) $2.4 \mathrm{~mm}$ from the fusion line.

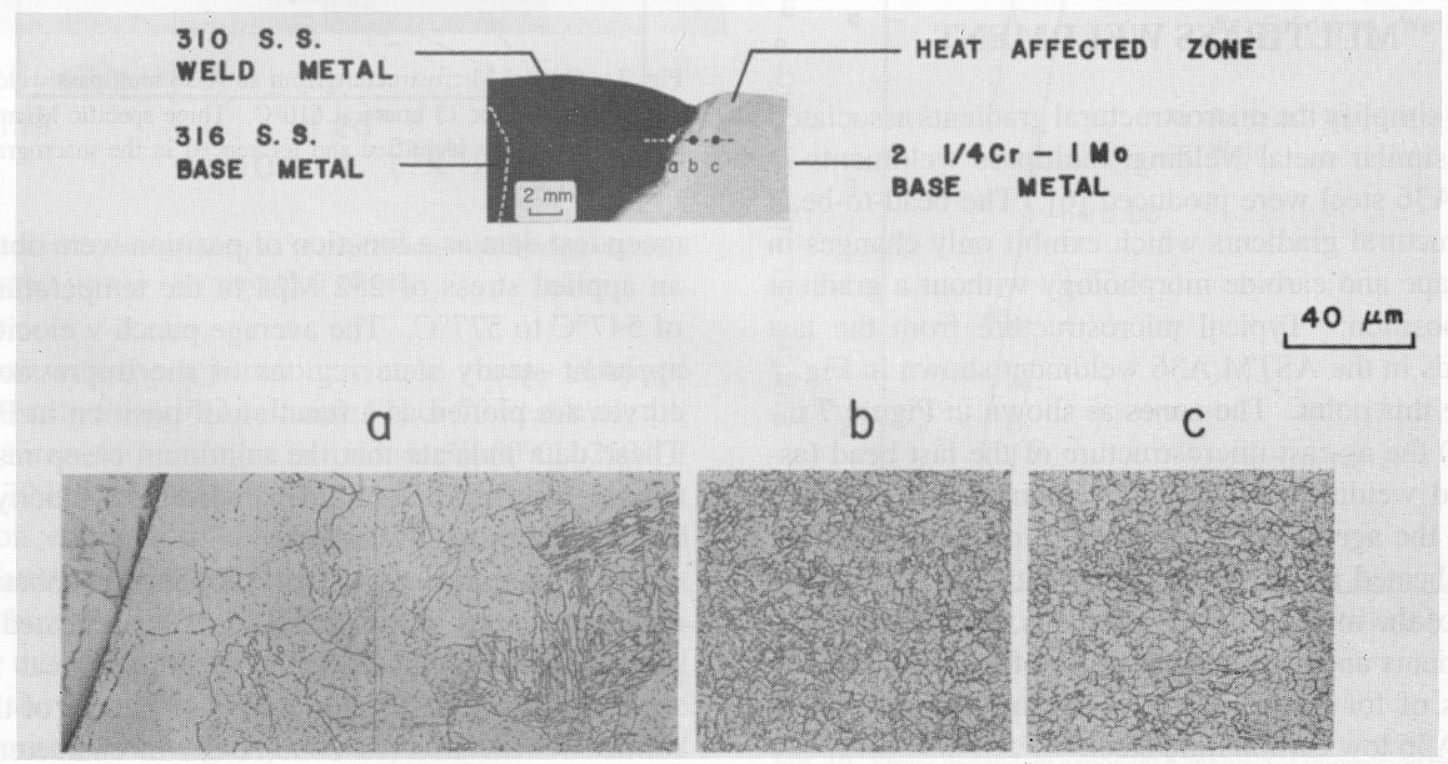

Fig. 5. Aged microstructures of dissilimar weldment as instrucred in Figure 4 for 120 hours at $675^{\circ} \mathrm{C}$. 

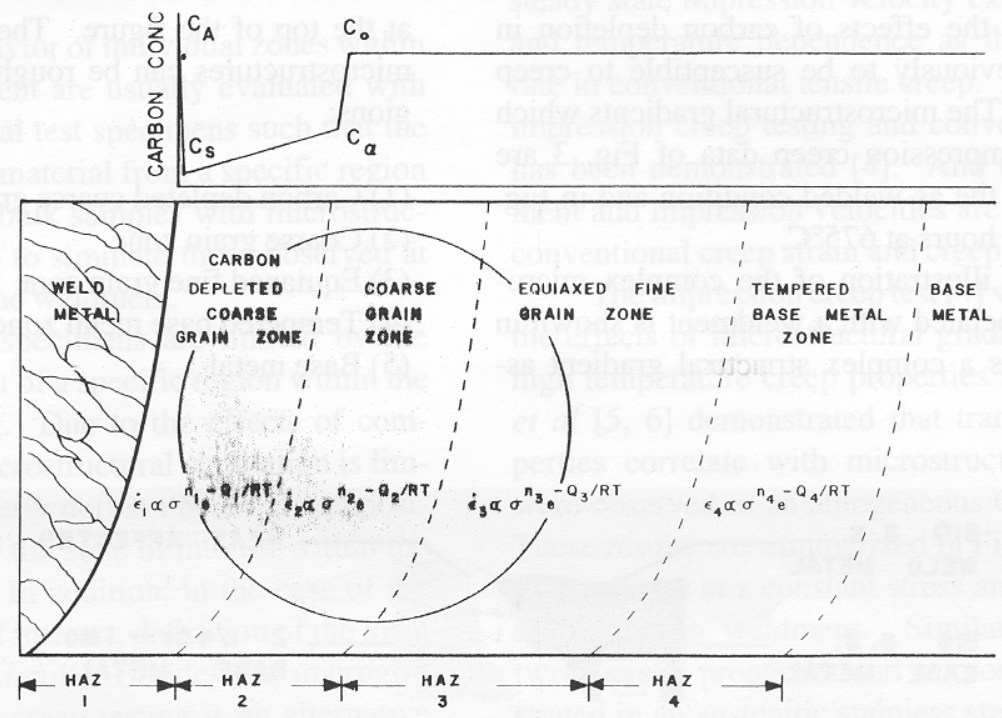

Fig. 6. Schematic illustration of microstructural and carbon gradients in $21 / 4 \mathrm{Cr}-1 \mathrm{Mo}$ steel adjacent to the austenitic fusion line. A shadowy circle represents the heterogeneous zones tested under the punch.

Also shown in Fig. 6, by the darked circle, is the size of the impresson creep test punch utilized by Gibbs et al [5]. This illustrates that due to the relative size difference between the punch and the zones, the spatial resolution of the test is limited by the punch diameter. Since the multiple microstructural zones exist within the deformation zone around the punch, the total observed deformation reflects the composite effects of the various microstructural zones. As a result the local creep rate at a specific critical region associated with failure still can not be sucessively obtained due to the limit in the size of punch.

\section{MULTIPASS WELDMENT}

To simplify the microstructural gradients associated with dissimilar metal welding, multipass weldments in ASTM A36 steel were produced [6]. The bead-to-bead microstructural gradients which exhibit only changes in grain shape and carbide morphology without a gradient in composition. Typical microstructure from the last two beads in the ASTM A36 weldment shown in Fig. 7 illustrate this point. The zones as shown in Figure 7 include (a) the as-cast microstructure of the last bead (assolidified weldment ) (B) a fine grained heat affected zone (c) the aged cast microstructure of the next-to-last bead (reheated as-solidified weldment). In addition to control of the microstructure gradients, low applied load requirements and short testing times offer additional advantages of for the selection of the low creep resistant ASTM A36 low carbon mild steel.

Impression creep data have been obtained on the ASTM A36 steel weldments shown in Fig. 7. Impression

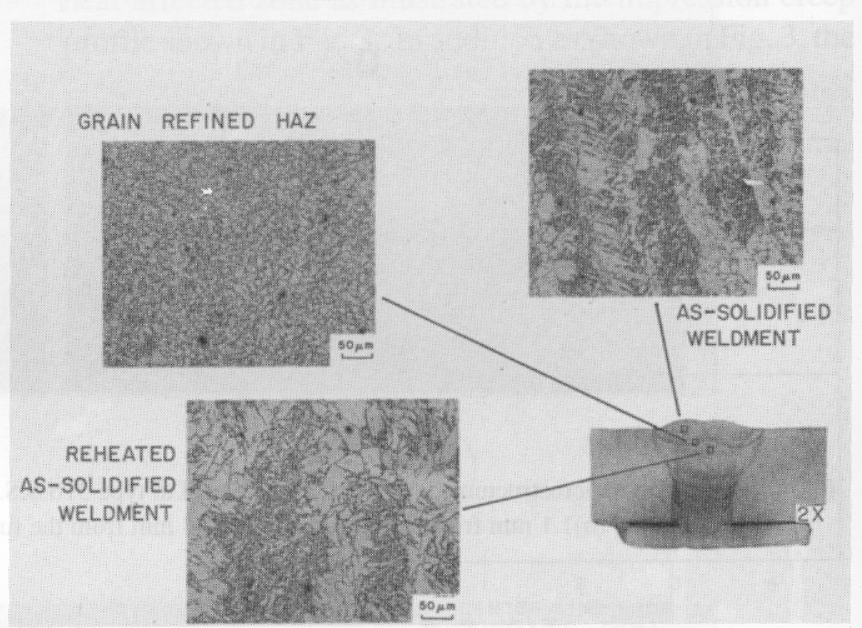

Fig. 7. Optical Microstructure from an A-36 multipass weldment Annealed for 13 hours at $610^{\circ} \mathrm{C}$. Three specific Microstructural zones are identified and referenced in the macrograph of the weld.

creep test data as a function of position were obtained at an applied stress of $252 \mathrm{Mpa}$ in the temperature range of $547^{\circ} \mathrm{C}$ to $577^{\circ} \mathrm{C}$. The average punch v elocity in the apparent steady state regions of the impression creep curves are plotted as a function of position in Figure 8. These data indicate that the minimum creep resistance, as evidenced by a maximum in impression velocity, occurs in the fine grain reheated zone.

Activation energy analysis has been obtained for creep velocities measured across the reheated as-cast zone, interfacial zone, and fine grain reheat affected zone(HAZ). The apparent activation energy of the grain refined reheat affected zone(HAZ) in characterized by a single value of about $84 \mathrm{kcal} / \mathrm{mole}$ as illustrated in the Arrhenius plot of Fig. 9. This value is reasonably 


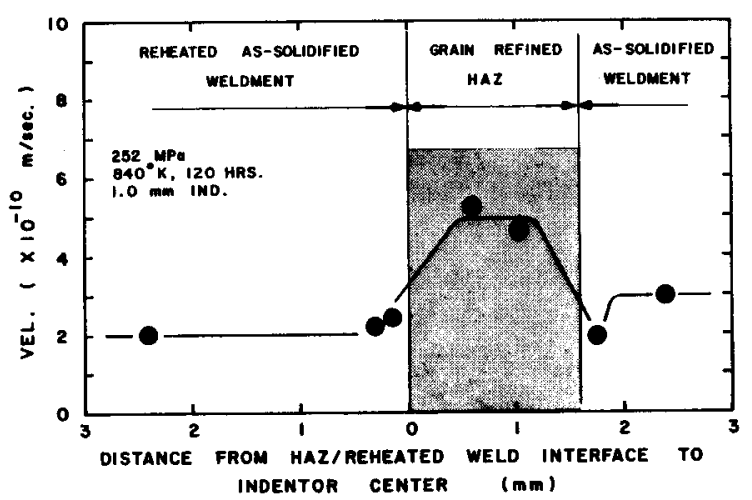

Fig. 8. A profile of the average punch velocity vesus a distance measured form the interface of the grain refined heat affected zone and the reheated as-solidfied weldment.

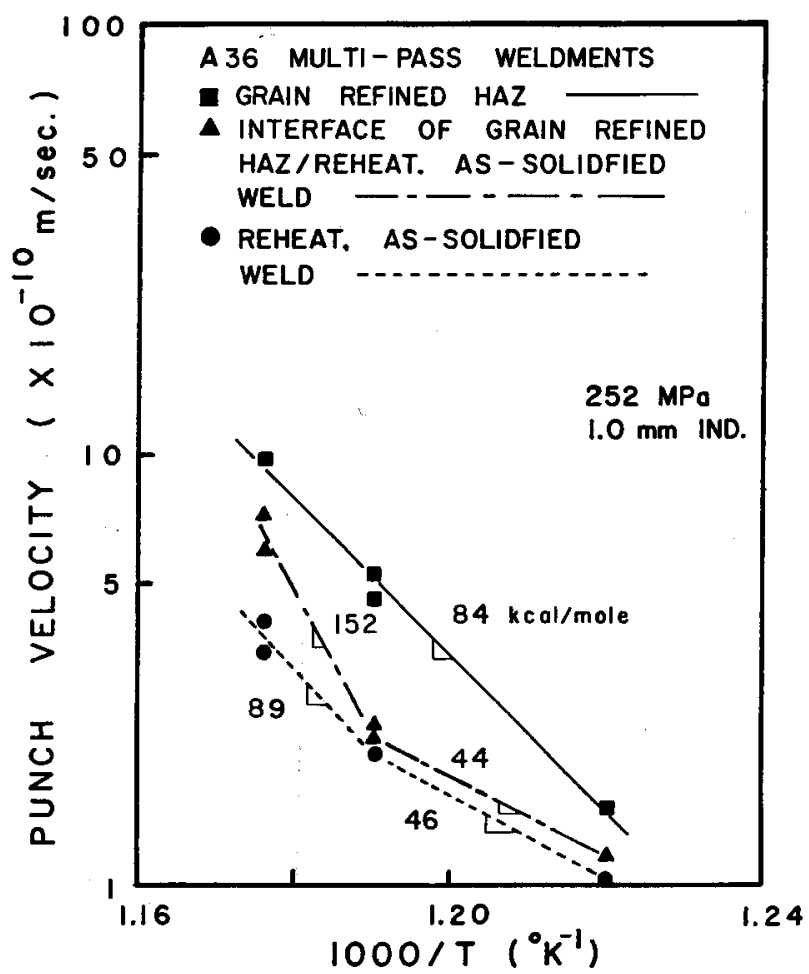

Fig. 9. Activation energy analysis of impression velocity data obtained across the two microstructural zones.

consistent with the apparent activation energy obtained in the literature e.g. $90 \mathrm{kcal} / \mathrm{mole} \mathrm{[7]} \mathrm{or} 70 \mathrm{kcal} / \mathrm{mole} \mathrm{[8]}$ for alpha iron, $65 \mathrm{kcal} / \mathrm{mole}$ in mild steel $\left(660^{\circ} \mathrm{C}-750^{\circ} \mathrm{C}\right)$ [9] and $79 \mathrm{kcal} / \mathrm{mole}$ in $\mathrm{Fe}$ [10]. In contrast the apparent activation energies in the region of the interface and the reheated as-solidified (as-cast) weldment are different as also shown in Fig. 9. At this point it is uncertain as to whether the different activation energies for the different regions shown in Fig. 9 reflect experimental scatter due to the limited data range, or actually reflect fundamental different due to the microstructural gradient.

The effect of stress on the impression velocity at a constant temperature of $567^{\circ} \mathrm{C}$ is shown in Figure 10 . Normally different values of the stress exponent, $n$, imply different mechanisms which control creep deformation. While limited in scope, these data show that the stress dependence of all three zones could be described by an approximately constant stress exponent, $\mathrm{n}$, of 5.5 to 6.0 . It seems that local deformation is dominated by dislocation mechanisms. Because of the narrow stress range, a strong argument still presents that $\mathbf{n}$ may vary with microstructure. The preliminary impression creep test results on ASTM A36 indicate that the observed deformation rates are sensitive microstructural variations. In addition since the punch is smaller than the dimensions of the individual microstructural zones the shortcomings with the evaluation of the dissimilar metal weldments discussed above are removed.

\section{DISCUSSION}

Impression creep velocities determined from impression creep tests on traverses from reheated as-solidified weldment, through grain refined $\mathrm{HAZ}$ into as-solidified weldment in ASTM A36 exhibit the gradual transition from the fine grained zone to either cast zone. These results reflect either the single microstructure below the punch or the volume-fraction dependent average of two components. Based on analysis of the impression

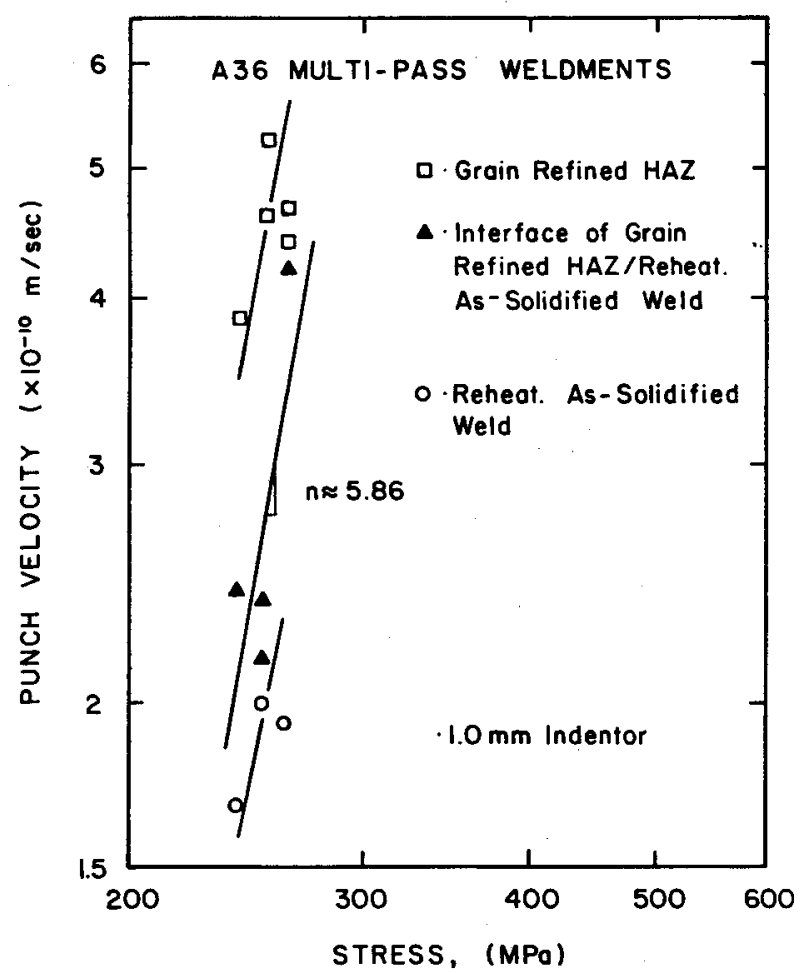

Fig. 10. Stress dependent exponent $n$ analysis of impression velocity data obtained across two microstructural zones at constant temperature $567^{\circ} \mathrm{C}$. 
creep data of Fig. 8, application composite modeling approach is limited to the region which includes the reheated solidified weldment and the grain refined zone. In contrast to the transition from the grain refined zone to the as-solidified weldment, which exhibites a local minimum in impression creep velocity at the interface between these zones, the transition in impression velocity is continuous in the region which will be used for composite model. The observed transition in creep behavior between the different zones in Fig. 8 directly reflects the gradients in microstructure shown in Fig. 11. In Fig. 11a the microstructural gradients are identified and the local minimum in impression velocity between the solidified weld metal and the grain refined zone is shown to correspond to the $0.3 \mathrm{~mm}$ transition zone identified in Fig. 11a. In contrast, Fig. $11 \mathrm{~b}$ shows a distinct separation of the solidified weld metal and the reheat affected zone which correlates with the smooth transition in observed impression creep behavior. As a result, the composite modeling approach can be applied to the microstructural zones identified in Fig. 11b. This analysis is conducted in order to properly understand the composite properties associated with the distinct zones within the microstructural gradient. Furthermore, unified creep equations of the various micro structural zones can be developed.

The deformation zone under the punch is associated with impression creep behavior. Hence the rate of punch penetration is controlled by the distribution of strain in the deformed zone below the punch in either homogeneous or heterogeneous microstructures [5]. In order to correlate the composite creep properties and activation energy which were mentioned previously, it is very important to know the total deformed geometry and the deformed volume fraction of each component. Unfortunately, the microstructure of the deformed cross-section around the punch does not appear different from that of the bulk after impression testing as illustrated in Fig. 12 for a sample of ASTM A36 deformed at $252 \mathrm{MPa}$ and $577^{\circ} \mathrm{C}$ for 62 hours. This phenomenon might be caused by dynamic recovery processes during impression creep testing.

A schematic drawing in Figure 13a illustrates the

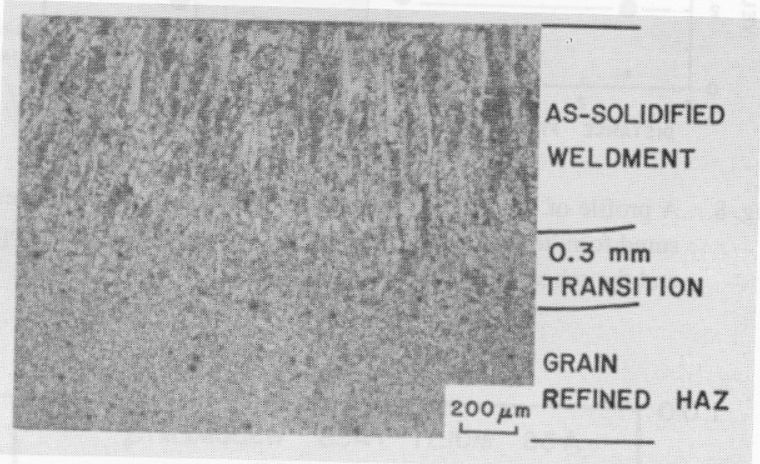

(a)

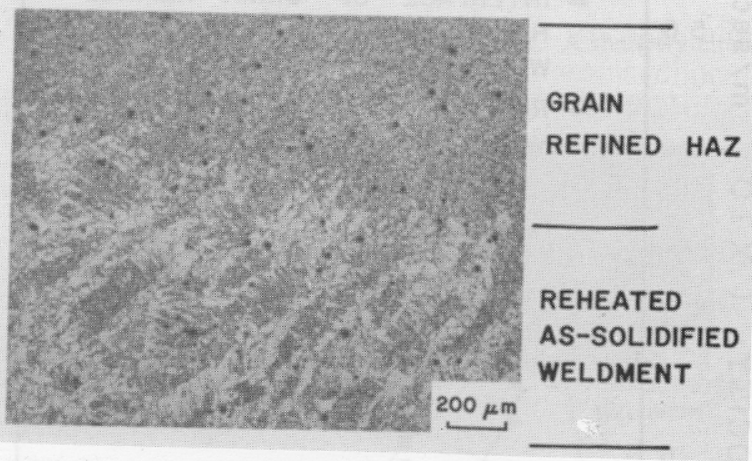

(b)

Fig. 11. Optical Micrographs of the interface between the fine grain reheat affected zone and the cast columnar structure of either the (a)as-solidified last bead, or (b)the reheated next-to-last bead.

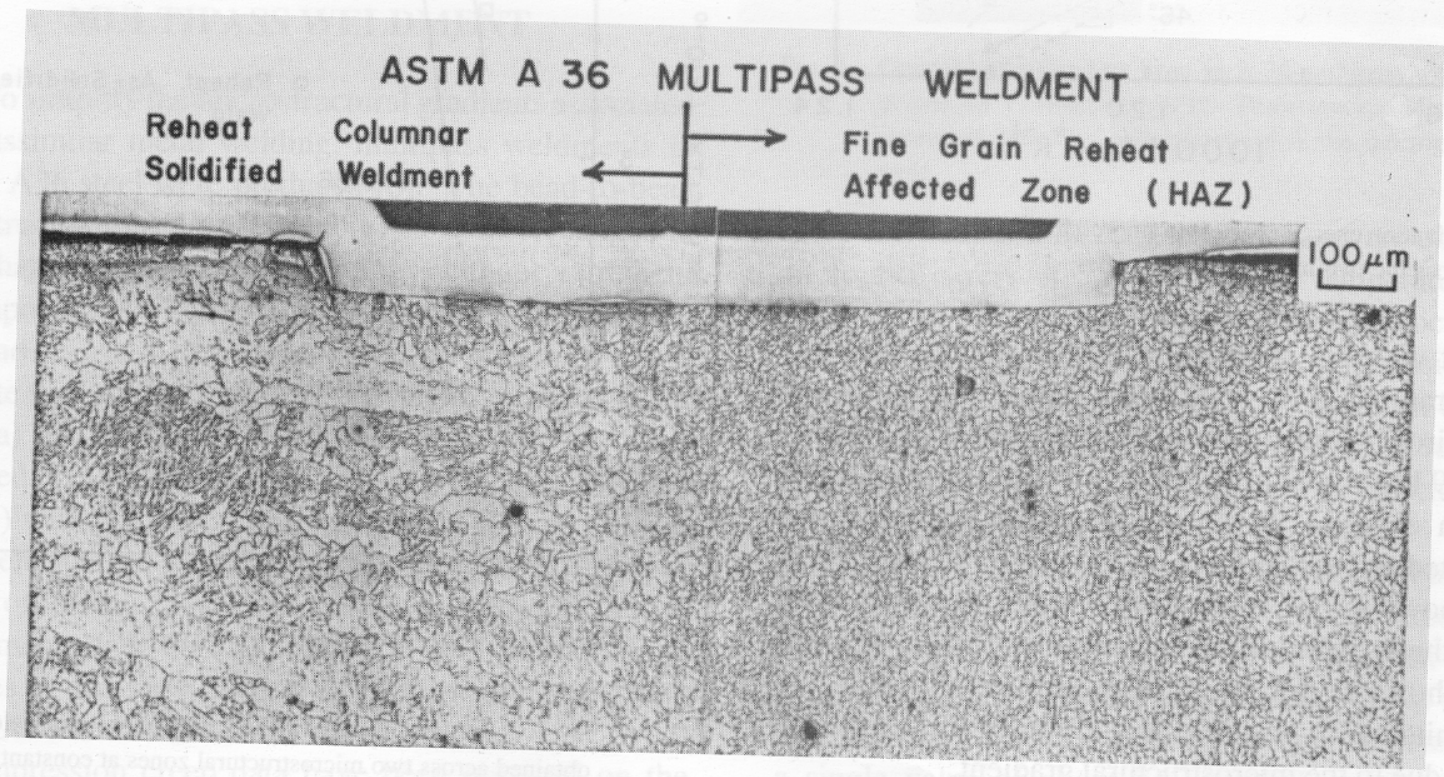

Fig. 12. Microstructure of cross section at the interface region after $62 \mathrm{hrs} \mathrm{impression} \mathrm{test} \mathrm{at} 577^{\circ} \mathrm{C}$ by a constant load of $252 \mathrm{Mpa}$. 


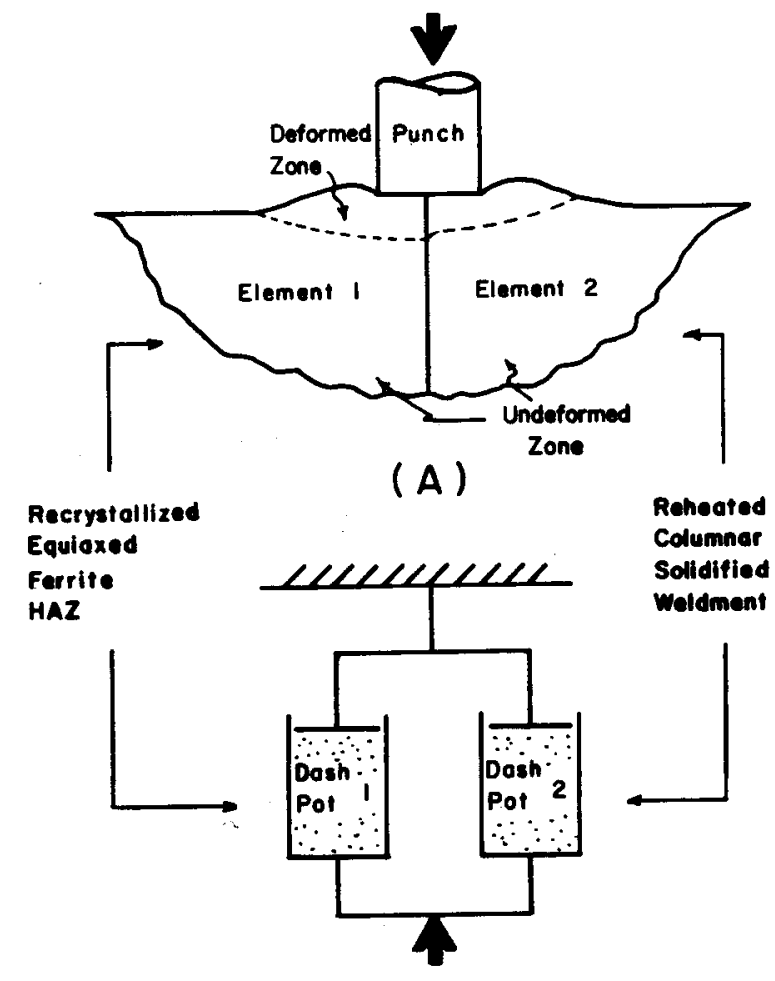

(B)
Fig. 13. Proposed dash-pot analogy of two-component composite. External applied stress is shown in arrow directions.

deformation behavior of a two-component composite under the punch. Composites have properties which are governed by the properties of the individual components. Both the elastic and plastic behavior can be varied via the volume fraction of the constituents. The multipass weldment can be viewed as consisting of two components, with the contributions of each depending on the relative position of the punch with respect to the interface. A simple model for initial analysis will be based on the following assumptions:

\section{Uniform deformation}

2. Isotropic properties

3. Iso-displacement

4. No microstructure change

5. Normalized stress with constant constraint factor, $\mathrm{K}$, 6. Neglet interfacial constraint

A mechanical analogy consists of two dashpots in parallel, for which displacement is time dependent as shown schematically in Fig. 13b. Each dashpot represents one of the constituents (equiaxed ferrite HAZ and columnar solidified weldment) and is interlinked and interdependent. Because of the equal impression velocity (equivalent to equal strain rate) imposed on the laminated composite, equal strain in deformation of this composite is imparted to each constituent. The strongest dashpot (high creep resistant microstructure) controls the flow rate of the two-dash pot model.

Chu et al have shown [4] that impression creep veloctiy, $v$, can be escribed as:

$$
\nu=(2 a) A\left(\frac{1}{k}\right)^{n}\left(\frac{\sigma}{E}\right)^{n} \exp \left(\frac{-Q}{R T}\right)
$$

where $A$ is a microstructure dependent parameter, $n$ is the stress exponent, $Q$ is the apparent activation energy, $\sigma$ is the applied stress, $K$ is the stress constraint correction factor, $a$ is the punch radius, and $E$ is the elastic modulus. In the case of 2-component composite from equation (1), the applied stress on the component 1 , which is assumed to be the recrystallized equiaxed ferrite HAZ in Fig. $11 \mathrm{~b}$ can be expressed by

$$
\frac{\sigma_{1}}{E_{1}}=\left(\frac{v_{1}}{2 a}\right)^{\frac{1}{n_{1}}}\left(\frac{1}{A_{1}}\right)^{\frac{1}{n_{1}}}\left(K_{1}\right) \exp \frac{Q_{1}}{n_{1} R T}
$$

and the applied stress on the component 2 , which would be the reheated columnar solidified weldment, can be expressed by

$$
\frac{\sigma_{2}}{E_{2}}=\left(\frac{v_{2}}{2 a}\right)^{\frac{1}{n_{2}}}\left(\frac{1}{A_{2}}\right)^{\frac{1}{n_{2}}}\left(K_{2}\right) \exp \frac{Q_{2}}{n_{2} R T}
$$

Based on the iso-impression-velocity dash-pot model (Fig. 13) without interface constraint

$$
v_{1}=v_{2}=v
$$

and

$$
\frac{\sigma_{c}}{E}=\left(\frac{\sigma_{1}}{E_{1}}\right) f_{1}+\left(\frac{\sigma_{1}}{E_{1}}\right) f_{2}
$$

where $C$ refers to the total behavior of the composite, $f_{1}$ the volume fraction of component 1 , and $f_{2}$ the volume fraction of component 2. If it is assumed that $E=E_{1}=E_{2}$, and $K_{1}=K_{2}=K$. Then one can derive that the constitutive equation for the stress exponent $n_{c}$ in the composite model can be described by

$$
\frac{1}{n_{c}}=\frac{P_{1} f_{1}\left(\frac{1}{n_{1}}\right)\left(\frac{v}{2 a}\right)^{\frac{1}{n_{1}}}+P_{2} f_{2}\left(\frac{1}{n_{2}}\right)\left(\frac{v}{2 a}\right)^{\frac{1}{n_{2}}}}{\sigma_{c}}
$$

and the constitutive equation for the activation energy, $\mathrm{Q}_{\mathrm{c}}$, in the composite model is given by 


$$
Q_{c}=\frac{f_{1} \sigma_{1}\left(\frac{Q_{1}}{n_{1}}\right)+f_{2} \sigma_{2}\left(\frac{Q_{2}}{n_{2}}\right)}{P_{1} f_{1}\left(\frac{1}{n_{1}}\right)\left(\frac{v}{2 a}\right)^{\frac{1}{n_{1}}}+P_{2} f_{2}\left(\frac{1}{n_{2}}\right)\left(\frac{v}{2 a}\right)^{\frac{1}{n_{2}}}}
$$

Where

$$
\begin{aligned}
& P_{1}=\left(\frac{1}{A_{1}}\right)^{\frac{1}{n_{1}}} K \exp \left(\frac{Q_{1}}{n_{1} R T}\right) \\
& P_{2}=\left(\frac{1}{A_{2}}\right)^{\frac{1}{n_{2}}} K \exp \left(\frac{Q_{2}}{n_{2} R T}\right)
\end{aligned}
$$

with equations (6) and (7) predictions of the relationship of $n_{c}$ and $Q_{c}$ to punch velocity can be obtained for various assumed volume fractions of each component along with the data of Figs. 9 and 10. These results may gain some insight from this mathmatical prediction.

\section{CONCLUSIONS}

1. Impression creep reveals the local creep properties as a function of position in weldments.

2. The apparent activation energy of the equiaxed ferrite grain structure within the reheat affected zone(HAZ) is consistent with values obtained from conventional creep testing.

3. Microstructural gradients associated with bead-to-bead variations in multipass weldment of A-36 provide an ideal material for analysis with appropriate two-com- ponent composite models.

4. The qualitative analysis shows composite $\mathrm{Q}_{c}$ and $\mathrm{n}_{\mathrm{c}}$ as a function of applied stress, punch velocity and volume fraction can be predicted mathmaticallly.

5. The localized creep rates can be determined within the microstructure gradient, then proper prediction of the service life for metal joints can be obtained.

\section{REFERENCE}

1. K. Tanala, M. Sato, T. Ishilawa, "Fatique COD and short crack arrest test", Proceedings of international conference on fracture toughness testing, The Welding Institute, London, June, 1982.

2. I.J. Chilton, A.T. Price, B. Wilshire, Metals Technol ogy, Sept., Vol.11, 1984, P.383

3. R.W. Evans, B. Wilshire, Mechanics of Materials, Vol. 4. No.1, 1985, P.51

4. S.N.G. Chu, J.C. Li, Journal of Material Science, Vol.12, 1977, P.2200

5. W.S. Gibbs, S.H.Wang, D.K. Matlock and D.L. Olson, Welding Journal, Vol.64, No.6, 1985, P.153s

6. S.H. Wang, Internal CSM Report at Colorado School of Mines, July 1986.

7. J. Cadek, M. Pahutova, K. Ciha and T. Hostinsky, Acta. Metall., Vol.17, June 1969, P.803

8. Yoichi Ishida, Ching-Yao Cheng and John E.Dorn, Trans. of AIME, Vol.236, July 1966, P.964

9. M.R. Nagy, M.M. EL-Sayed, and A.A. Mohamed, Mat. Sci. Eng., Vol.60, 1983, L13-L16

10. H. Conrad, J. of Metals, July 1964, P.582. 